\title{
La pastoral popular en el pensamiento del padre Rafael Tello. Una contribución desde Argentina a la teología latinoamericana
}

Omar César Albado*

\section{Resumen}

El presente artículo ofrece un acercamiento al pensamiento teológico de Rafael Tello. Se trata de un teólogo argentino, desconocido fuera de su país, quien reflexionó durante cuarenta años sobre la importancia de la cultura y del pueblo para la evangelización de América Latina. Siendo uno de los teólogos fundadores de la línea conocida como «pastoral popular», el autor de este artículo se propone presentar algunas de las principales cuestiones que articulan su reflexión. Al indagar en su concepción de cultura popular y de cultura moderna, nos propone adentrarnos en un debate que lejos de estar resuelto resurge con renovada vitalidad en el actual desafío evangelizador, político y social que atraviesa nuestro continente.

\footnotetext{
Doctor en Teología Dogmática por la Facultad de Teología de la Pontificia Universidad Católica Argentina. Profesor en el Seminario «Nuestra Señora de Nazaret» de la diócesis de San Nicolás de los Arroyos (hasta el año 2000) y en el seminario Interdiocesano de la Encarnación en Resistencia (hasta el año 2002). Actualmente enseña en el Instituto de Formación Sacerdotal Santo Cura de Ars de la arquidiócesis Mercedes-Luján, en el Instituto Superior Docente y Técnico San Pedro y San Pablo de la diócesis de Campana y en la Facultad de Teología de la Pontificia Universidad Católica Argentina. En esta última forma parte de los siguientes grupos de investigación: «Judíos y cristianos en los procesos culturales del mundo helenístico-romano», «Investigación y reflexión sobre la cultura popular actual» e «Historia y perspectiva de la teología en Argentina», todos ellos pertenecientes al Instituto de Investigaciones Teológicas de la Facultad de Teología. Contacto: omar_albado@yahoo.com.ar.
} 


\title{
Palabras claves
}

Rafael Tello, pastoral popular, cultura popular, cultura moderna, hombre concreto.

\section{The popular pastoral in the thought of the priest Rafael Tello. A contribution from Argentina to Latin American theology}

\begin{abstract}
This article presents an approach to the theological thinking of Rafael Tello. He is an Argentinian theologian, unknown beyond the borders of his country, who reflected upon the importance of culture and of the people for the evangelization of Latin America during forty years. Being Rafael Tello one of the founding theologians of the current known as "popular pastoral», the author of this article proposes to present some of the main issues which articulate his reflection. When he looks into his conception of popular culture and of modern culture he proposes that we go into a debate which, far from solved, reappears with renewed vitality in the current evangelizing, political and social challenge our continent is undergoing.
\end{abstract}

\section{Keywords}

Rafael Tello, popular pastoral, popular culture, modern culture, concrete man.

\section{La teología de la pastoral popular}

Concluido el Concilio Vaticano II, comienza a cristalizarse en Argentina una corriente teológica que propone pensar la relación entre Dios y la historia. Es un grupo que crece impulsado por un anhelo común en Latinoamérica: la liberación de los pueblos. Pero en Argentina esta búsqueda toma una forma particular. Si bien la acentuación sigue estando sobre el pueblo, la puerta de acceso no será la liberación sino la cultura. Esta acentuación no supone necesariamente una oposición entre ambos conceptos (como se quiso 
poner de relieve en el post-Puebla, a partir de 1979, sin hacer ninguna distinción crítica), sino perspectivas de análisis diversas sobre una misma realidad. La corriente argentina privilegia una comprensión del pueblo en donde su estilo de vida (es decir, su cultura) se comprendiese dinámicamente y no estáticamente. Por ello, como señala Sebastián Politi:

entre las ciencias sociales a las cuales se acudía para acceder a una comprensión «científica» de la realidad, se priorizaba la historia por sobre la sociología, la psicología social u otras. La insistencia sobre la necesidad de conocer los procesos históricos, sus protagonistas y alternativas, en orden a una correcta ubicación en la realidad del pueblo, marcó el estilo de trabajo de estos teólogos. La sustancia viviente de lo real, de los pueblos, de los hombres y de sus luchas y esperanzas, solo puede ser percibida en su propio dinamismo y en el devenir concreto de sus aspiraciones, realizaciones y fracasos ${ }^{1}$.

Surge entonces en Argentina una corriente teológica que recibió distintos nombres: «escuela argentina de teología», «teología del pueblo», «teología de la cultura», «teología de la pastoral popular». Sus principales mentores fueron Lucio Gera, Rafael Tello, Justino O'Farrell. Otros acompañaban la reflexión pero, sin duda, eran ellos quienes proponían el rumbo que la misma debía tomar. El punto de encuentro para que estos teólogos desarrollaran grupalmente su pensamiento fue la COEPAL (Comisión Episcopal para la Pastoral). Creada en 1968 por el episcopado argentino, esta comisión tenía la tarea de pensar cuál era la pastoral más conveniente para llevar adelante en la Argentina. Presidida por Mons. Angelelli, Mons. Marengo y Mons. Zaspe la COEPAL pronto se convirtió en un órgano que agrupaba a nivel nacional a sacerdotes, religiosos, religiosas y laicos. En este contexto toma forma, por primera vez, muchas de las formulaciones teológicas de la teología del pueblo. Luego de su disolución en 1973, los teólogos de la COEPAL siguieron pensando en esta línea, pero ya no dialogando entre sí, sino haciendo cada uno su camino. En esta dispersión incidieron situaciones intra-eclesiales, como así también la coyuntura política del país.

1 Sebastián Politi, Teología del pueblo. Una propuesta argentina a la teología latinoamericana. $1967-$ 1975 (Buenos Aires: Castañeda, 1992), 217. 
Señalábamos arriba que la teología del pueblo prioriza la historia por sobre otras ciencias sociales. Las razones de esta prioridad son varias. En primer lugar, se trata de percibir en los procesos históricos de qué modo el pueblo comprendió la liberación. El interrogante primero no es qué piensan los teólogos sobre la liberación, sino qué entiende el pueblo por liberación. La respuesta implicaba un doble movimiento: estar cerca del pueblo y estudiar la historia para ver cómo es su presencia a lo largo de quinientos años. En segundo lugar, de este modo de comprender la historia emerge también un modo de entender la cultura. Ella es un estilo de vida dinámico, con la movilidad que le imprime la adaptación a la coyuntura. Pero también con rasgos comunes que se mantienen en el tiempo y que le dan una identidad propia. En este sentido, la historia del pueblo genera no solo acontecimientos sino también un estilo de vida peculiar, es decir, una cultura. En tercer lugar, surge la pregunta: ¿̇qué tiene que ver Dios con la historia y la cultura? ¿̇a fe en Dios se modifica según la cultura a la que se pertenezca? Creer en Dios dentro de ciertos parámetros culturales, ìimplica reconocer que una cultura puede acentuar aspectos de Dios que otra considera secundarios? En definitiva, żla cultura cambia a Dios o Dios cambia a la cultura?

Luego de la dispersión de 1973 cada uno de los autores intentó pensar esta problemática desde sus peculiaridades y sus búsquedas personales y comunitarias. Aquí elegimos presentar germinalmente la reflexión de Rafael Tello, uno de los teólogos más fecundos y a la vez menos conocidos de la pastoral popular. Muchas de sus obras, como señalamos un poco más adelante, siguen inéditas aún. En ella encontramos un pensamiento que no es fácil de sintetizar. Por eso este artículo se propone hacer una presentación en sociedad, consciente de los límites que pueda tener no solo por el espacio, sino también por la complejidad de los temas.

\section{Pincelazos de una vida}

Rafael Tello fue un teólogo argentino que nació en La Plata el 7 de agosto de 1917 y murió en Luján el 19 de abril de 2002. En 1944, cuando tenía 27 años, se recibió de abogado. Ingresó al seminario de la arquidiócesis de Buenos Aires en 1945 y se ordenó sacerdote el 23 de septiembre de 1950. Trabajó activamente como asesor de 
Juventud Universitaria Católica y, a partir de 1958, como profesor en la Facultad de Teología de Buenos Aires. Se lo conocía como un hombre muy inquieto, de inteligencia aguda y penetrante, con propuestas pastorales originales. Estuvo cerca de muchos sacerdotes del Movimiento de Sacerdotes para el Tercer Mundo brindándole su consejo y compañía; integró la COEPAL alentando, junto a otros, un momento particularmente fecundo de la pastoral argentina; influyó notablemente en la elaboración del documento VI sobre pastoral popular en el Documento de San Miguel, un trabajo de 1969 en donde los obispos argentinos hicieron la recepción de Medellín; creó e impulsó en 1975 la peregrinación juvenil a Luján, que congregó a veinticinco mil jóvenes en su primera edición y que, en la actualidad, sigue convocando a más de un millón de personas.

En marzo de 1979 comienza una nueva etapa de su vida: a raíz de un conflicto con el arzobispo de la arquidiócesis de Buenos Aires, toma la decisión de retirarse de la vida pública y comienza un periodo de reclusión que se mantendrá hasta el día de su muerte. Abandona su actividad como profesor en la Facultad de Teología y solo mantiene contacto con algunos sacerdotes que le son muy cercanos. Aunque las causas de este alejamiento son difíciles de sintetizar en pocas palabras, es necesario aclarar que Tello no abandonó el ministerio sacerdotal ni la autoridad eclesiástica le retiró las licencias. Sin embargo, desde su reclusión voluntaria siguió pensando una teología que tuviese incidencia en la evangelización del pueblo latinoamericano. Para ello, junto al grupo de sacerdotes cercanos, impulsó la creación de una asociación privada de fieles que bajo la protección de la Virgen de Luján trabajara por la evangelización de los más pobres y por el fortalecimiento del cristianismo popular. Esta asociación fundada en los inicios de la década del '80 perdura hasta hoy.

La vida de Rafael Tello está marcada por dos momentos bien definidos: una etapa pública y una etapa oculta. Cada una de ellas tiene sus matices particulares que justificarían un estudio por sí mismo. Sin embargo, podemos afirmar que ambas están atravesadas por la única intención de promover pastoralmente y justificar teológicamente la conveniencia de una pastoral popular para la evangelización de América Latina. Este artículo se propone ofrecer algunos aspectos del pensamiento de Tello sobre la pastoral popular. 
La breve semblanza que hemos presentado tiene como intención ubicar la reflexión en un contexto biográfico. Ambos son desconocidos en el mundo teológico de América Latina. Por ello mi trabajo quiere aportar un granito de arena para que podamos escuchar su voz y preguntarnos por la relevancia actual de su pensamiento.

Muchos de los textos citados en este artículo no se han publicado todavía. Fueron incluidos para alcanzar una mayor explicitación del pensamiento de Tello garantizando, por supuesto, la fidelidad de la fuente. Pero si bien es verdad que la mayor parte de su obra aún se encuentra inédita, hay que señalar que paulatinamente comenzó a promoverse la publicación de sus escritos ${ }^{2}$ al tiempo que se dio inicio a un proceso de recepción de su pensamiento ${ }^{3}$.

\section{Volverse al hombre concreto}

La comprensión de la pastoral popular que propone Rafael Tello puede tener varios accesos. Nuestra opción toma como punto de partida una orientación postulada por el magisterio universal y que

Hasta la fecha se han editado Rafael Tello, La Nueva Evangelización. Escritos teológico-pastorales (Buenos Aires: Ágape, 2008) y Rafael Tello, Pueblo y cultura I (Buenos Aires: Patria Grande, 2011).

Anterior a las ediciones consignadas en la nota anterior cf. Marcelo González, «Teología de la historia desde la perspectiva argentina. La contribución de Lucio Gera y Rafael Tello», Stromata 58 (2002): 238-246; Marcelo González, La reflexión teológica en la Argentina, 1962-2004: apuntes para un mapa de sus relaciones y desafíos hacia el futuro (Córdoba: Universidad Católica de Córdoba, 2005). También Víctor Fernández, «Con los pobres hasta el fondo. El pensamiento teológico de Rafael Tello», Proyecto 36 (2000): 187-205; Víctor Fernández, «El Padre Tello: una interpelación todavía no escuchada», Vida Pastoral 236 (2002): 34-40. Posterior a las ediciones hay que destacar el libro de Enrique Bianchi, Pobres en este mundo, ricos en la fe (Sant 2,5). La fe de los pobres en América Latina según Rafael Tello (Buenos Aires: Ágape, 2012) y la publicación de diversos artículos: Enrique Bianchi, «No anteponer nada al amor del pobre sino al amor de Cristo, del cual deriva», Vida Pastoral 295 (2011): 4-10. Los artículos citados a continuación pertenecen todos a Omar César Albado, «La condescendencia divina en la teología de la pastoral popular del padre Rafael Tello», Vida Pastoral 281 (2010): 19-27; «Volverse al hombre concreto: una aproximación a la cultura popular en la teología del padre Rafael Tello», Vida Pastoral 283 (2010); "La teología afectiva como modo de conocimiento del pueblo en la pastoral popular del padre Rafael Tello», Vida Pastoral 287 (2010): 24-28; «Algunas características de la teología afectiva según el padre Rafael Tello», Vida Pastoral 288 (2010): 20-25; «El hombre hace cultura. Reflexiones en torno a la distinción entre cultura subjetiva y cultura objetiva en la teología de Rafael Tello», Vida Pastoral 296 (2011) 21-26; «El hombre es dueño del sábado. La cultura subjetiva como generadora de un estilo de vida en la teología de Rafael Tello», Vida Pastoral 299 (2011): 12-19; "No le pongan el corazón a las riquezas: la posición de Rafael Tello frente a la cultura moderna», Vida Pastoral 302 (2011) 4-10; «No se puede servir a dos señores: la primacía de la riqueza en la cultura moderna según el padre Rafael Tello», Vida Pastoral 306 (2012) 40-47; «Fe, cristianismo y humildad: núcleos teologales de la pastoral popular del padre Rafael Tello», Teología 107 (2012): 61-77. 
Tello asume y aplica a la situación latinoamericana y Argentina: la necesidad exigida por las condiciones contemporáneas de volverse al hombre concreto. Esta actitud es reclamada por el espíritu que anima al Concilio Vaticano II y retomada explícitamente Juan Pablo II en Redemptor hominis. Precisamente en el $\mathrm{n}^{\circ} 13 \mathrm{c}$ de esa encíclica el papa afirma: "Se trata del hombre en toda su verdad, en su plena dimensión. No se trata del hombre "abstracto" sino "real", del hombre "concreto", "histórico". Se trata de "cada" hombre». Las comillas internas de la cita ponen de relieve la contraposición entre dos concepciones antropológicas, que difieren básicamente en que la primera considera al hombre como un ser al que se puede tratar con los mismos principios, en cualquier parte del planeta, sin importar las diferencias históricas y culturales que condicionan la existencia del sujeto, aspecto que acentúa la postura del papa. Tello se hará cargo de esta enseñanza, no como un tema más del magisterio y de la teología, sino como una línea transversal y programática que, en su criterio, afecta tanto al corpus teórico de la enseñanza como a la práctica pastoral.

El Concilio Vaticano II inaugura, en la interpretación de Tello, un giro antropológico profundamente renovador. Comentando los textos conciliares y su prolongación en Juan Pablo II, dirá que la cuestión actual es la de volverse:

no hacia el hombre abstracto, considerado según cierta idea o concepción de lo que él es ni mirado solo según su naturaleza (lo que seguiría siendo abstracto) sino hacia el hombre concreto, real, histórica e individualmente existente, es decir todo el hombre y cada hombre nacido de mujer, creado por Dios y por Él llamado a participar de su vida que es eterna: y por esto mismo todo el hombre, en todas sus dimensiones -eterna y temporal, espiritual y corporal, individual y comunitaria- todos los hombres y cada uno de ellos ${ }^{4}$.

Las parejas de la cita que relacionan natural-sobrenatural destacan que la distinción existe pero nunca para contraponer. Es el mismo y único hombre el que vive en este tiempo y el que es salvado 
en el más allá. El texto no deja espacio para desentenderse de la situación concreta de una persona, como si allí no se manifestara la voluntad de Dios que se plenificará en el más allá.

Sin embargo, el giro antropológico no debe confundirse con el giro antropocéntrico. Este último es el eje de la cultura moderna e implica la negación de Dios en cualquiera de sus formas y la exaltación del hombre por el hombre mismo. Aquí la inmanencia encierra al hombre exclusivamente en los límites de espacio y del tiempo sin esperar nada de lo sobrenatural. Tello deja en claro que el Concilio no hace suya ni directa ni veladamente las tesis modernas y liberales sobre el hombre que la Iglesia rechaza explícitamente. La Iglesia se vuelve al hombre concreto, no por lo que este puede llegar a ser (por su posición social o por su educación), sino porque sencillamente es hombre. Lo otro puede venir después, pero de ningún modo es condición para decidir la atención sobre él. Su dignidad no depende de si sabe leer o escribir, si tiene luz o gas natural, sino solo y simplemente porque es hombre creado por Dios. En esto se diferencia el giro antropológico del antropocentrismo. De ningún modo se niegan los beneficios de la modernidad, pero ellos no son condición de posibilidad de la dignidad del hombre. Él es digno previo a la posesión de esos bienes y, por supuesto, lo es aun cuando nunca los llegue a poseer. Tello lo dirá de este modo:

Esto nos permite penetrar más en el sentido de la operación conciliar: no la consideración primaria de la sociedad, ni de la sociedad cristiana, para abordar al hombre; no la consideración primaria del hombre como parte de un todo que es la comunidad; no el aprecio del hombre en cuanto susceptible de llegar a una cierta formación por la educación. El concilio se vuelve hacia el hombre simplemente mirado en sí mismo, tal como es, creado, dirigido providencialmente y redimido por Dios, hacia el hombre concreto, históricamente existente, concebido por mujer y nacido de una madre. Pero ese hombre, todo hombre, es persona -única creatura querida por Dios por sí misma- y libre. Persona cuya libertad hay que respetar ${ }^{5}$.

El hombre concreto en el que piensa Tello es comunitario. Este es un dato importante que complementa la novedad que aporta el giro 
antropológico. Sin ceder a las tendencias colectivistas, Tello sostiene claramente que la persona alcanza su plena realización cuando no ve limitada su disposición natural a vivir en comunidad, pues el hombre concreto no es el sujeto considerado aisladamente, sino en su relación comunitaria. Encontramos una nueva diferencia con el antropocentrismo moderno, en donde prima tanto el individualismo como el colectivismo, según la versión a la que se adhiera. Dirá Tello:

\begin{abstract}
Esta es la concepción doctrinal del Concilio. La personalidad no es algo abstracto, que constituye al individuo en un último absoluto, sino al contrario, completa, cierra y ratifica la individualidad en su ser propio, pero es relativa (como siempre lo es aún en la Santísima Trinidad) a la comunión de personas. Y esto es concorde con la enseñanza común sobre Dios, último fin del hombre y sobre la caridad como forma de la amistad ${ }^{6}$.
\end{abstract}

La pastoral popular de Tello, en nuestra opinión, tiene un punto de partida que nos abre perspectivas interesantes. Por un lado, recoge la enseñanza magisterial desde el Concilio Vaticano II en adelante, entendiéndola como una adaptación a los tiempos actuales sin renegar (ni siquiera veladamente) de la tradición. Por otro lado, rechaza cualquier reducción antropológica, sea el individualismo o el colectivismo. Las parejas conceptuales referidas a la relación Dios-hombre (natural-sobrenatural) y a la relación hombre-hombre (individual-social) ponen de manifiesto una tensión que de anularse compromete la concepción antropológica cristiana.

\title{
4. La primacía de la cultura
}

El hombre concreto se distingue para Tello porque vive en una cultura. El teólogo argentino focaliza su reflexión en este aspecto porque es el que permite conocer al sujeto en su singularidad específica. Estudiando la naturaleza humana se conocen aquellos aspectos que los hombres tienen en común. En este sentido un europeo, un asiático, un africano y un latinoamericano no se diferencian. Aquello que los distingue es la cultura, lo que permite comprenderlos en lo que tienen de propio. Así, es común a los seres humanos alimen-

Ibíd., Tomo I, nota 33. 
tarse. Pero el acto de comer se vivirá de diversas maneras según las costumbres culturales. Algo semejante ocurre con la fe cristiana. Existe una fe común, en la que todos concuerdan, pero el modo de expresarla difiere según la cultura a la que se pertenezca.

Esta afirmación de la primacía de la cultura será central en la reflexión de Tello. Se inscribe así en la línea específica de la teología argentina que se comenzó a gestar a fines de la década del 60 y que se conoció, entre otros títulos, como la «teología del pueblo». Nombres como los de Lucio Gera, Justino O'Farrell y posteriormente Juan Carlos Scannone, quedaron vinculados a un pensamiento que pone el acento más en la cultura que en la liberación. Preocupados por comprender la realidad latinoamericana desde la historia, y no tanto desde los aportes brindados por la sociología y las demás ciencias sociales, resignificaron el sentido de la categoría pueblo, generando un marco teórico que se distingue claramente de los lineamentos propuestos por la teología de la liberación predominante.

Pero lo que debería haber sido una legítima discusión de escuelas fue presentada, en el post-Puebla, como una confrontación destinada a dirimir concepciones eclesiológicas al interior de la Iglesia. Se sostenía que Puebla había optado por el lenguaje alternativo de la cultura para reemplazar las afirmaciones radicalizadas de la teología de la liberación. Carlos Galli es uno de los primeros es desmentir ese malentendido señalando que, desde el análisis del pensamiento de Gera, la disociación entre liberación y evangelización de la cultura es inadmisible ${ }^{7}$. Por su parte, Marcelo González señala que las diferencias entre ambas posiciones son reales. Recuerda que la teología de la liberación ha sacado a la luz algunas falencias de la teología argentina, tales como la tendencia a ver más las continuidades que las rupturas y los conflictos, la deficitaria consideración de los factores económicos y de las perspectivas sociológicas de análisis, la ausencia de una crítica de la religión. Pero de ahí a señalar una oposición irreductible entre ambas es ilusorio. Para González «la importancia fundamental que tanto en las ciencias sociales como en

7 Cf. Carlos María Galli, «La teología latinoamericana de la cultura en las vísperas del Tercer Milenio», en El futuro de la reflexión teológica en América Latina (Bogotá: CELAM, 1996), 243-362. 283293. 
la teología latinoamericana han adquirido en los últimos años tanto la cultura como la religión, son una muestra de la intuición profética de la escuela argentina. El pensamiento de Lucio Gera, Juan Carlos Scannone y tantos otros representantes de la escuela argentina impide que se los identifique sin más con posturas restauracionistas y conservadoras $»^{8}$.

El propio Tello desecha esta dicotomía, porque la cultura a la cual hace referencia en su teología «abarca todo lo que resulta del medio histórico que constituye a cada pueblo concreto» ${ }^{9}$. Trabajar por el fortalecimiento de la cultura no es sostener un orden conservador y tradicional, que modifique la situación solamente en función de los intereses de los poderosos, sino consolidar el reconocimiento de la identidad propia del pueblo que se gestó en América Latina y que, por su dinámica interna, tiende a la libertad y a la liberación. Existe oposición si pensamos en la cultura del dominador como única forma de expresión. Allí, sin duda, no habrá anhelos de liberación. Sin embargo, para Tello la oposición no existe cuando pensamos la relación entre cultura popular y liberación. Esta cultura hay que entenderla no como la producción de objetos culturales que pueden conocerse separados del sujeto que los produce, sino como todo aquello que el hombre realiza en su medio histórico, aun lo más común y ordinario. Si la cultura fuesen solo los objetos producidos sí podría ser considerada distractiva y opuesta a la liberación, «por lo menos en cuanto se acepta de hecho el marco de la dominación dentro del cual se establece la dedicación a la promoción cultural» ${ }^{10}$. Tello entiende la cultura popular como una «disposición, estilo de vida, sistema de valores, del pueblo como comunidad humana, medio histórico en la cual y desde la cual el hombre actúa. Y lo que actúa, así sea lo más común y ordinario, pertenece a su cultura» ${ }^{11}$. La cultura popular es mucho más que las expresiones típicas o folklóricas con las que muchas veces es asociada casi exclusivamente. Tello utiliza la expresión «medio histórico». Hay que entenderla como el ámbito real en el que el hombre se expresa cotidianamente, con su bagaje

Marcelo González, «Aportes argentinos a un pensamiento teológico latinoamericano inculturado. Memoria, presente y perspectivas de un cauce teológico», Stromata 58 (2002): 123.

10 Ibíd., 147.

11 Ídem. 
de costumbres ancestrales y actuales, pero también con el sello de la opresión que lo somete a llevar una vida que no desea y que se manifiesta de maneras muy diversas.

Consideradas así las cosas es patente que la cultura popular no solo no se opone a la liberación sino que es su fundamento y también su gran instrumento, instrumento imprescindible. Si se entiende liberación como «ser sí mismo», la liberación implica necesariamente apoyarse sobre la cultura del sujeto. Por tanto no tiene base válida la oposición de una «teología» a la otra ${ }^{12}$.

\section{La originalidad de la cultura popular latinoamericana}

Planteada la situación de este modo Tello propondrá, como el camino más eficaz para que la pastoral popular luche por la liberación del pueblo latinoamericano, el fortalecimiento de la cultura popular. Ahora bien, ¿̇qué es la cultura popular? Trazaremos algunos rasgos que nos permitan delinear la concepción de Tello.

Ante todo se trata de la cultura propia de América Latina, que la distingue no solo de la de otros continentes sino también de aquella que quiere imponerse hegemónicamente en estas tierras. Sobre esta última cuestión volveremos un poco más adelante. Pero si esta cultura es propia de estas tierras y no de otras debe tener algunas características que la vuelvan original. Muchos intelectuales europeos desde la historia, la antropología y la sociología se han preocupado por estudiar la existencia de una cultura popular en las distintas épocas y culturas. ¿̇En qué se diferencia con la de América Latina según la entiende Tello? ¿Qué tiene de original respecto de las otras?

A nuestro entender la diferencia se encuentra en que para Tello la cultura popular de América Latina es una forma permanente de resistencia, surgida de la primera evangelización de la Iglesia a la opresión de los poderosos. Tello afirmará que la primera evangelización no formó comunidades eclesiásticas sino un pueblo. En el pueblo 
todos tienen un lugar, nadie es excluido. Y eso la Iglesia lo propició cuando bautizó sin distinción e indiscriminadamente, sin exigir una pertenencia a las estructuras de la institución ni la incorporación a una cultura que le era extraña. El bautizado se quedaba entre los suyos y ello no era impedimento para considerarlo verdadero cristiano.

Ello no implica una mirada romántica sobre la historia que ignore los atropellos cometidos en nombre de Dios y de la fe. Lo que se sostiene aquí es que el pueblo hizo suya la fe que le entregaba la Iglesia y la incorporó a su vida según sus esquemas culturales, los cuales, sin duda, diferían mucho de los del conquistador español. Sin embargo, los evangelizadores no obligaron a los pueblos originarios a abandonar su cultura para recibir la fe. Y cuando quisieron hacerlo tuvieron que asesinar o quedar perplejos ante la astucia paciente del pueblo que se sometía, pero no claudicaba en su forma de ser. Esto no justifica la violencia, sino que muestra que la violencia no necesariamente cambia o destruye una cultura. Por eso, en medio de la tragedia que por momentos significó la conquista española, la fe no fue un elemento accidental.

El análisis de una cita de Tello, elegida entre tantas, puede ayudarnos a comprender el alcance de estas afirmaciones: «En los últimos cinco siglos junto a una cultura moderna que ha ido desarrollando sus caminos, ha perdurado juntamente en nuestras tierras una cultura pobre, que es esencialmente cristiana (cf. Documentos de Medellín, Puebla y Sto. Domingo) $»^{13}$.

De la cita extraemos algunos elementos para el análisis. En primer término tenemos la referencia a la duración temporal de la cultura popular: cinco siglos. Sin duda la alusión es a la llegada de la corona española al continente. Tello sostiene que los pueblos originarios que se encontraban en este suelo resignificaron el sentido de su existencia, a partir de la fe recibida en el bautismo, lo cual no implica que quedaron asimilados a las costumbres españolas. Creen en el mismo Dios que los conquistadores y misioneros, pero a su manera. La fe les permite subsistir en una situación hostil y tener un 
lugar en el orden social, aunque este lugar sea el último. Los pueblos originarios ven que su mundo material y simbólico destruido puede encontrar un nuevo espacio de formulación en la fe que anunciaban los misioneros. Tello así lo explicaba en una charla a sacerdotes en 1977:

\begin{abstract}
En la fe que se le anuncia, el indio va a encontrar estos elementos: el indio pasa a formar parte de una nueva sociedad. Se le destruyó su sociedad y al ser bautizado entra en una nueva sociedad. Es un miembro vivo de una sociedad. Tendrá el último grado de la sociedad, pero no es excluido de ella. El indio bautizado es un cristiano; y en una sociedad cristiana eso significa mucho. Ahí están las raíces de la libertad, el indio bautizado sabe que es hijo de Dios exactamente igual que el noble o el virrey, es hijo de Dios. Allí nace el sentimiento de igualdad y de libertad que queda en nuestros pueblos. Entra como miembro de una sociedad, y en esa sociedad el indio va a adquirir un nombre, es alguien. Aunque es el último es alguien y en otro aspecto es mucho, porque es hijo de Dios ${ }^{14}$.
\end{abstract}

La cultura popular, tal como la conocemos, podríamos decir que es nueva. Ha sido transformada por el cristianismo y su fe se asienta en la Cruz, en la Virgen y en los santos con una devoción inalterable. Pero es también la continuidad de una cultura ancestral que occidente no ha podido desterrar en estos cinco siglos de esfuerzos. Es una cultura mestiza, donde las creencias atávicas perviven resignificadas en el culto cristiano.

En segundo lugar, quisiéramos destacar la relación estrecha que Tello establece en la cita entre pobre y cristiano. Están puestas allí como dos notas distintivas de la cultura popular y no meramente accidentales. Nótese la expresión «esencialmente» para referirse al cristianismo de esa cultura popular pobre.

La cuestión de la pobreza no es accidental u ornamental para Tello, fundamentalmente porque ella es parte de la vida de Cristo. Cristo no solo fue solidario con los hombres en sus necesidades espirituales y corporales, sino que asumió como propio un estilo 
de vida desprendido de las riquezas. No solo se hizo hombre y se ocupó personalmente de los pobres, sino que «quiso agregar más: se hizo hombre pobre, y desde su condición de pobre realizó su obra de misericordia, redención y liberación» ${ }^{15}$. Tello saca de aquí una consecuencia inapelable: los pobres, en sentido estricto, completan la Pasión de Cristo y son hechos cooperadores de la salvación; y la Iglesia debe seguir las enseñanzas de su Maestro.

Encontrar en América Latina un pueblo compuesto en su mayoría por pobres que han sido bautizados no es un dato menor para Tello. Su propuesta pastoral no es suprimir la pobreza de los pobres, sino amar a ambas realidades como ama la cruz de Cristo, de la que la pobreza forma parte. Se trata de estar al lado de los pobres renunciando a las alianzas con los poderes que manejan el mundo y rechazando el poder de la riqueza. No es que Tello esté en contra de la promoción social de los pobres. Ella es muy importante, pero no ocupa el primer lugar. La lucha contra la pobreza adquiere en el teólogo argentino características peculiares: «Forma parte de la lucha contra la pobreza la difusión y fortalecimiento del cristianismo popular, que desde este particular punto de vista: es el más alto medio de humanización; es el más eficaz medio de defensa y promoción de la cultura popular; se opone a la secularización de la vida del hombre; corrige el individualismo hoy creciente» ${ }^{16}$.

Cristianismo y pobreza no caminan separados. En América Latina tenemos una pobreza real en un pueblo que es cristiano según la cultura popular. Podremos argüir que la pobreza es fruto de la opresión de los poderosos y que debemos combatirla con todas nuestras fuerzas. Tello no niega ese combate. Solo que para él los pobres no son un motivo de escándalo sino un don de Dios.

Finalmente, quisiera destacar el paralelismo conflictivo que el teólogo argentino establece entre cultura popular y cultura moderna. Ese paralelismo se da desde la llegada de los españoles al continente. En los últimos cinco siglos, dirá Tello, la cultura moderna «desarrolló»

Rafael Tello, Pobres y pobreza, hoy, Cofradía de Luján, folleto $n^{\circ} 5$, sin fecha, $n^{\circ} 12$ (cursiva en el original).

16 Ibíd., nº 56 
sus caminos en tanto que la popular «perduró». No es casual la utilización de los verbos. «Desarrollar» tiene que ver con el progreso, con la realización de un proyecto, con el acrecentamiento. En cambio, «perdurar» hace referencia a durar mucho, a subsistir, a mantenerse en el mismo estado. Los verbos caracterizan la situación de ambas culturas. La que se ha «desarrollado» pudo imponer sus criterios y hacerlos avanzar en la estructuración social del continente. Ha generado un sistema de opresión que hubiese sido imposible sin ese desarrollo. En ese contexto la cultura popular «perdura». El término no hay que entenderlo en un sentido peyorativo o avalando un pasivismo ante un destino inexorable, sino como la descripción de una forma de resistencia frente al poder dominante. Lo que Tello está señalando es que ambas culturas existen en un mismo espacio histórico. Prestar atención a los verbos utilizados en la cita nos permite comprender que para Tello ambas culturas existen en la actualidad, comparten un mismo espacio histórico y que tienen entre sí una relación conflictiva, la cual se expresa en forma pacífica o violenta según las circunstancias históricas. Sobre esto volveremos más adelante.

\section{Dos culturas ${ }^{17}$}

Pero en América Latina el espacio histórico es compartido básicamente por dos culturas principales: la popular y la moderna. En sus escritos Tello caracteriza abundantemente ambas culturas. Haré aquí una presentación sintética en orden a nuestros propósitos.

La cultura moderna (a la que por metonimia suele llamar "cultura ilustrada» en muchos lugares) es la que propone la exaltación absoluta del hombre sin ninguna relación con lo sobrenatural. Esto vale tanto para el marxismo, que tiene el ateísmo como base de su sistema, como para el capitalismo, que privatiza la fe en Dios como una opción individual. Así la cultura moderna será caracterizada como secularista, individualista y conformadora de un orden real. Quiero prestar especial atención a esta última nota, pues la considero determinante para comprender la distinción de las culturas.

17 Tello reconoce la existencia de una tercera cultura a la que llama eclesiástica. Simplemente la menciono pero no la incorporaré a la argumentación por razones de espacio. 
En primer lugar, detengámonos en el análisis del término orden, que Tello aplicará a ambas culturas. No olvidemos que estamos hablando de cultura y toda cultura produce una estructuración social-temporal con jerarquización de valores. Con la palabra orden se refiere a la propuesta de organización social, política, económica e ideológica hecha por un grupo humano, como estructuración de su existencia comunitaria. Es decir, cada cultura propondrá un orden de valores condicionado por los fines que se propone alcanzar. La cultura moderna y la cultura popular tienen un orden diverso y por eso son culturas realmente distintas. Ambas pueden coexistir aun cuando una triunfe sobre la otra y produzca contenidos y hechos para dar la impresión de que el orden no deseado es de segunda categoría y hasta sería bueno que desaparezca.

Orden real no se refiere a aquello que tiene una existencia verdadera y efectiva, como si la cultura moderna fuese la única que existe en tanto que la popular solo es una entelequia, una expresión de deseo o simplemente una realidad a construir. Aquí real se entiende en un sentido filosófico-teológico y proviene de res, palabra latina que significa cosa. Se refiere en un sentido amplio a todo aquello que es exterior al hombre y que fue pensado para que esté a su servicio y no esclavizándolo (como el ejemplo del sábado en el evangelio). Tello hace suyo este término, de acuerdo al sentir del Concilio (cf. GS 26), para poner de manifiesto que en la cultura moderna se da una primacía del mundo de los objetos y de las instituciones por sobre las personas.

Pero aún más: cuando Tello señala la preeminencia de las cosas por sobre las personas no hay que entenderlo como si hablara exclusivamente de los elementos materiales que rodean a un sujeto. "Cosa» no es, en primer lugar, el universo instrumental de objetos que el hombre utiliza para vivir (por ejemplo, los utensilios cada vez más sofisticados por el avance de la tecnología), sino la conformación de un orden social en donde lo más importante es que el hombre se someta al poder del dinero, de la producción, del comercio, del mercado y, en definitiva, a las instituciones creadas para sostener este orden. La significación del término «cosa» se amplía y profundiza para referirse a un sistema que apunta «en último término a sostener un orden de leyes e instituciones o a procurar la producción u obtención de bienes materiales, o a asegurar la prestación de servicios 
útiles, y a todo esto el Concilio llama orden real, es decir de cosas, destinado a salvaguardar cosas ${ }^{18}$. La simple explicación de la palabra nos ubica en un universo que sobrepasa ampliamente la referencia más acotada al uso de los instrumentos propiciados por la cultura moderna y nos adentra en la compleja trama de la modernidad, que no se desarticula solo con una crítica coyuntural.

En este contexto la cultura popular es caracterizada por oposición a la moderna: no es secularista, no es individualista y pide un orden social personal. Pero la oposición no es accidental o reaccionaria, sino consecuencia de un origen histórico diverso. La cultura popular es la cultura de los pueblos latinoamericanos, que encontraron en la fe cristiana un elemento fundamental para reconstruir su universo simbólico-mítico destruido por la conquista. La fe cristiana les permitió resignificar sus costumbres y creencias ancestrales en un nuevo orden social que les era hostil y los oprimía. Para Tello esta actitud se mantiene en la historia, tomando formas distintas según las circunstancias. Nunca se incorporaron al orden social foráneo, no solo porque no se lo permitieron sino fundamentalmente porque lo sentían ajeno. Esto tiene consecuencias también en el modo de vivir la fe. Ella no asumirá la forma religiosa eclesiástica sino que se insertará en los moldes temporales del universo simbólico-mítico resignificado. Y fue la primera evangelización la que permitió, al decir de Tello, esta resignificación constituyéndose en un cristianismo verdadero.

En ese universo el orden personal ocupa un sitio privilegiado, pues da cuenta de la primacía de la persona por sobre cualquier otra realidad. Las instituciones y los objetos están a su servicio, del mismo modo que el sábado está al servicio del hombre (cf. Mc 2,27). «Es decir [un orden] donde la persona humana sea reconocida como el valor mayor, y donde cada una y todas las cosas (todo lo que no es persona) esté subordinado a los hombres» ${ }^{19}$. La búsqueda de la prioridad de la persona por sobre las instituciones y cosas, en general, conformó y caracterizó al pueblo latinoamericano desde los inicios de su existencia. Así lo entiende Tello cuando afirma:

18 Rafael Tello, Fundamentos de una Nueva Evangelización. Tomo I, nota 33, op. cit.

19 Rafael Tello, La pastoral popular y Santo Domingo, $\mathrm{n}^{\circ} 258$, inédito. 
el pueblo quiso siempre el reconocimiento de la dignidad de todo hombre, y por la fe recibida supo que la fuente de esa dignidad estaba en que cada hombre era hijo de Dios y había sido llamado a la vida en Dios, y esto de un modo muy especial por el bautismo (por eso también la Iglesia otorgaba el bautismo de un modo muy amplio). El pueblo unía así la dignidad del hombre y la fe en Dios, lo temporal y lo religioso, pues aquello se funda en esto. Y el orden social deseado coincidía por tanto con lo que después el Concilio llamaría orden personal ${ }^{20}$.

La cuestión de los dos órdenes toma una dimensión particular porque la opción por la cultura implica la opción por la liberación. «Al orden personal se opone el orden social "real" en el cual el "hombre" es subordinado a alguna "cosa"; es el orden vigente en nuestras sociedades modernas, y el que rigió también durante la conquista y la colonización en las que los hombres de condición social inferior quedaron sujetos a los intereses de las clases superiores ${ }^{21}$. No se puede proponer una liberación auténtica si no se opta por la cultura popular. La cultura moderna está incapacitada para ofrecerla, por la sencilla razón de que ella es la que genera la opresión. Por ello la solución no pasa porque la cultura popular tenga acceso libre a los instrumentos de la modernidad pues, a la larga, produce mayor dominación y sometimiento. La cuestión de fondo pasa por reconocer que la cultura popular tiene un proyecto histórico propio y viable que no necesita ser convalidado por los parámetros de la cultura moderna.

\section{La importancia del proceso histórico}

La presencia de las dos culturas no es una deducción lógica sino la consecuencia del estudio del proceso histórico. El proceso histórico es muy importante porque hace referencia a «un movimiento que tiene un punto desde el cual parte y otro hacia el que se dirige, con un sentido determinado» ${ }^{22}$. Para Tello el proceso histórico no está manejado por el azar o por el arbitrio de fuerzas desconocidas sino por la libertad del hombre. Y por ser libre tiene intenciones bien precisas que buscan concretarse en las sociedades.

20 Rafael Tello, Pastoral popular: nota $(\mathrm{g}), 389$, inédito.

21 Rafael Tello, La pastoral popular y Santo Domingo, $\mathrm{n}^{\circ} 258$, op. cit.

22 Rafael Tello, Sobre cultura moderna. Cuadernillo complementario $2, \mathrm{n}^{\circ} 68$, inédito. 
La opción no es caprichosa ni circunstancial. A lo largo de la obra de Tello es muy común encontrarnos con estudios históricos minuciosos que se proponen encontrar el origen de una actitud cultural, no en causas teóricas sino en opciones existenciales. En una charla afirmó claramente el convencimiento de que si hay cultura hay historia y viceversa. "La cultura depende a su vez en gran parte de la historia. Todo núcleo histórico va a producir una cultura ${ }^{23}$. El conocimiento de la historia es uno de los principales elementos para comprender no solo la cultura moderna, sino también la popular. Tello se adentra en la historia para bucear en las culturas y se preocupa por conocer los modos culturales porque están insertos en la historia. Esta relación tan estrecha de ida y vuelta convierte al estudio de la historia en un camino privilegiado para juzgar sobre los modos de actuar y descubrir las características peculiares de las distintas culturas, pues en ellas se ponen en juego las diversas subjetividades y las búsquedas comunes de los hombres.

Pero Tello no se acerca a la historia para estudiarla como una sucesión cronológica de hechos (que por supuesto no desdeña), sino para analizarla atendiendo especialmente a los procesos humanos y seculares que la van configurando como una realidad cultural. Por ello la historia será estudiada no como cronología sino como proceso. No se trata de indagar solo en las épocas recientes, como si los anhelos de los hombres se hubiesen originado en dos o tres generaciones anteriores a la nuestra. Hay que animarse a hurgar en un pasado que no siempre trae consigo presagios venturosos y buscar la raíz en orígenes más remotos. La historia nos alcanza ese conocimiento y ella debe interesar a la Iglesia, no para acrecentar su erudición académica sino para evangelizar con mayores frutos: «Aquí consideramos la historia no por sí misma sino en función de la nueva evangelización. Es lo que hizo el Papa al lanzarla en Santo Domingo en octubre del 84. Y con razón pues la evangelización es gracia, pero la gracia supone la natura, y la natura y su acción no se presentan concretamente sino modificadas, determinadas, por la historia y la cultura» ${ }^{24}$.

23 Rafael Tello, Desgrabación charla 25 de agosto de 1994, inédito, s/n.

24 Rafael Tello, Consideración de nuestra historia, n 1 , inédito (cursiva en el original). 


\section{El conflicto de culturas}

Señalábamos más arriba que para Tello la convivencia entre cultura moderna y cultura popular es conflictiva. Por supuesto que a la hora de medir fuerzas la cultura moderna lleva casi siempre las de ganar, porque en ella se encuentran los que en distintos grados son más ricos y poderosos. La cultura popular lo sabe y por ello el conflicto no siempre se manifiesta de forma visible y violenta. La cultura popular es consciente que el aparato represor de la cultura moderna no dudará en actuar cuando vea cuestionados sus intereses. El conflicto tomará, pues, la forma de una resistencia silenciosa en donde se privilegia la astucia y el pasar desapercibido para mantener su estilo de vida. Tello insiste en que no hay que dejarse engañar pensando que esa actitud responde a una resignación fatalista. Recién señalábamos por contraposición las características de una y otra cultura. Para Tello dicha contraposición es mucho más que una descripción social que nos ayuda a reconocer actores diversos, sino que pone de manifiesto la existencia de un conflicto permanente y subyacente. Ese conflicto revela que el antagonismo más profundo a la cultura moderna no proviene de otras formas culturales ilustradas que se presentan como una alternativa, sino de la cultura popular. Taxativamente el teólogo argentino afirma: «Sin embargo, con ello hay que tener una diligente advertencia: nuestra cultura popular tiene, consideraras sus líneas principales, la máxima oposición a la cultura moderna» ${ }^{25}$.

No obstante, esa máxima oposición no siempre es percibida. Para Tello la razón reside en que se desconoce la existencia de la cultura popular como un estilo de vida, que configura un sistema de valores que lleva a actuar de una manera determinada (cf. GS 53). Se acepta que existe una cultura popular que tiene determinadas expresiones objetivas. Cantan, bailan, construyen, trabajan. Todo eso lo hace con su peculiar modo de ser, pero de ninguna manera esas expresiones constituyen un estilo de vida que jerarquiza valores. Esas expresiones son toleradas en tanto y en cuanto puedan ser orientadas a los esquemas de la cultura moderna. No es que se ignore la presencia de la cultura popular, sino que se intenta anexarla a otro proyecto 
cultural que no es el propio. Se la ve en su exterioridad pero no se la comprende en sus movimientos interiores.

Ese desconocimiento hace que la cultura popular no juegue un papel relevante en el conflicto cultural, según las concepciones dominantes en el mundo occidental. Tello explica las cosas de otra manera. Para él el corazón de la cultura moderna es necesariamente capitalista y este, por muchas razones, debe ser privado. A esta concepción se opone el marxismo colectivista, quien exige que el capital para la producción deba ser para el Estado. Habitualmente se asume que la confrontación cultural se da entre estas dos concepciones en apariencia diametralmente opuestas. Sin embargo, para Tello no son sino dos caras de una misma moneda pues el marxismo, a la vez que se presenta como el gran enemigo, no hace más que sostener la malicia interna de la cultura moderna al no cuestionar las bases en las que se sustenta. En este esquema bifronte cuando la concepción marxista cae se asume inmediatamente que solo queda la primera, la cual simplemente habrá que corregir en sus excesos y defectos. El juicio de Tello se completa con el siguiente análisis:

\begin{abstract}
Este modo de ver no advierte dos cosas: que la cultura marxista no es contradictoria (oposición absoluta) a la ilustrada o moderna, sino solo contraria (pertenecen a un mismo género), y que la verdaderamente contradictoria a ella es nuestra cultura popular (no secularista contra secularista, no-individualista contra individualista, exigiendo un orden social personal contra otra que lo niega); por esto negar la marxista no implica afirmar la individualista moderna, en cambio, afirmar la popular sí implica negar la moderna, y viceversa ${ }^{26}$.
\end{abstract}

Con el reconocimiento explícito de la cultura popular como un estilo de vida capaz de generar un sistema peculiar de valores, Tello introduce un nuevo actor no solo en el ámbito de la evangelización, sino también en el político. Un actor que es desconocido en su capacidad transformadora y considerado dependiente de otras formas culturales más perfectas, porque la concepción dominante no toma en serio lo que ocurre con la vida de los pueblos latinoamericanos y los que vivimos en estas tierras nos sujetamos demasiado a aquellos

26 Ibíd., 131 (cursiva en el original). 
esquemas mentales. «Esto ocurre de hecho, y en gran parte, porque en los países centrales no es conocida verdaderamente nuestra cultura popular, y en los nuestros, en cuanto dependen de aquellos o de la cultura moderna universalizada, tampoco» ${ }^{27}$.

Señalamos la función de la cultura popular como actor político, pues su oposición máxima es a un modo histórico de organizar la vida humana. No es solo oposición a una concepción religiosa, sino a una estructuración temporal de la sociedad. Aquella caracterización de una cultura que propicia un orden real y otra que busca un orden personal, tiene consecuencias en el modo en que la Iglesia debe concebir la evangelización, pero también en la organización política de una comunidad. El conflicto de culturas no se reduce a un conjunto de ideas intercambiables que en definitiva no proponen modificar el orden real de la modernidad, como ocurre entre la concepción capitalista privada y el marxismo colectivista. Para Tello cultura moderna y cultura popular son estilos de vida incompatibles. La cultura popular, que predomina en el pueblo latinoamericano, cuestiona con sus actitudes vitales el orden social impuesto por la modernidad. Y ello tiene consecuencias políticas, no porque primariamente se busque modificar un sistema de gobierno o se reclame la participación en un partido político, sino porque se cuestiona la primacía de las cosas (en el sentido amplio que expusimos anteriormente) por sobre las personas. Como vemos, la acentuación del conflicto de culturas no es una dilación de la lucha contra la injusticia ni un abandono de la búsqueda de liberación. Lo que Tello reclama es luchar por estas causas aprendiendo de la lucha histórica que el pueblo ha realizado y realiza.

\section{Perspectivas y desafíos}

Hemos realizado un recorrido por algunos de los elementos que conforman la pastoral popular de Rafael Tello. Como cierre proponemos algunas perspectivas y desafíos que se presentan a la reflexión teológica actual desde este pensamiento.

27 Ídem. 
En primer lugar, la constante vigilancia para no dejarnos seducir por esquemas interpretativos pensados en otras geografías y desde otras culturas. Sin duda no se trata de desconocer a los pensadores de otras latitudes. Además de ingenua esta actitud incitaría peligrosamente la formación de un gueto. El desafío es mirar ante todo la realidad histórica de los hombres y mujeres que viven en América Latina y explicarla desde ellos. Quizás en algún momento haya que inventar categorías nuevas; quizás haya que echar mano a aportes de los que viven en otra realidad; quizás debamos desempolvar conceptos clásicos. Todo vale si nuestro esfuerzo está centrado en mirar al hombre concreto que habita en estas tierras.

En segundo lugar, Tello supera la dicotomía entre cultura y liberación. Más precisamente entre cultura popular y liberación. Una pastoral popular que no sea crítica de la cultura moderna correrá el riesgo de no comprender al hombre de América Latina. La primacía que la cultura asume en su reflexión nos pone ante el desafío de discernir cuándo la cultura libera y cuándo es un analgésico que mantiene el orden establecido. Y aquí un criterio se nos impone con fuerza: estamos invitados a bucear en el mundo de los pobres y de su pobreza como una situación de vida que tiene sentido por sí misma. La pobreza de los pobres está para que nos adhiramos a ella como un destino compartido y no solo para verla como un mal a erradicar. Una adhesión a la que somos llamados aunque, paradójicamente, nunca seamos pobres como los pobres.

En tercer lugar la ruptura de la dicotomía entre cultura y liberación ha puesto de relieve el conflicto de las culturas. Este conflicto recorre el entramado histórico de todas las épocas y, por supuesto, también de la actual. Pero el reconocimiento del conflicto no es un aval para la violencia. Que la violencia existe es innegable. Lo que digo es que no nos es posible usarla como excusa para redimir de la opresión, pues ella no es aceptada por el pueblo como un medio ordinario de liberación. Generalmente el pueblo padece la violencia e históricamente ha tomado otros caminos para resistirla: la astucia, el perfil bajo, el silencio, la fiesta. Detenernos en esas actitudes implica un esfuerzo renovado para conocer el espíritu pacífico del pueblo y sus formas de resistencia. 


\section{Bibliografía}

Albado, Omar César. «Fe, cristianismo y humildad: núcleos teologales de la pastoral popular del padre Rafael Tello». Teología 107 (2012): 61-77.

. «No se puede servir a dos señores: la primacía de la riqueza en la cultura moderna según el padre Rafael Tello». Vida Pastoral 306 (2012): 40-47.

. «No le pongan el corazón a las riquezas: la posición de Rafael Tello frente a la cultura moderna». Vida Pastoral 302 (2011): 4-10.

. «El hombre es dueño del sábado. La cultura subjetiva como generadora de un estilo de vida en la teología de Rafael Tello». Vida Pastoral 299 (2011): 12-19.

. «El hombre hace cultura. Reflexiones en torno a la distinción entre cultura subjetiva y cultura objetiva en la teología de Rafael Tello». Vida Pastoral 296 (2011): 21-26.

. «Volverse al hombre concreto: una aproximación a la cultura popular en la teología del padre Rafael Tello». Vida Pastoral 283 (2010): 4-11.

- «La condescendencia divina en la teología de la pastoral popular del padre Rafael Tello». Vida Pastoral 281 (2010): 19-27.

- "La teología afectiva como modo de conocimiento del pueblo en la pastoral popular del padre Rafael Tello». Vida Pastoral 287 (2010): 24-28.

- «Algunas características de la teología afectiva según el padre Rafael Tello». Vida Pastoral 288 (2010): 20-25.

Bianchi, Enrique. Pobres en este mundo, ricos en la fe (Sant 2,5). La fe de los pobres en América Latina según Rafael Tello. Buenos Aires: Ágape, 2012. 
. «No anteponer nada al amor del pobre sino al amor de Cristo, del cual deriva». Vida Pastoral 295 (2011): 4-10.

Fernández Beret, Guillermo. El pueblo en la teología de la liberación. Consecuencias de un concepto ambiguo para la eclesiología y la pastoral latinoamericanas. Frankfurt-Madrid: VervuertIberoamericana, 1996.

Fernández, Víctor. «El Padre Tello: una interpelación todavía no escuchada». Vida Pastoral 236 (2002): 34-40.

. «Con los pobres hasta el fondo. El pensamiento teológico de Rafael Tello». Proyecto 36 (2000): 187-205.

Galli, Carlos María. «La teología latinoamericana de la cultura en las vísperas del Tercer Milenio». En El futuro de la reflexión teológica en América Latina, editado por el CELAM, 242-362. Bogotá: CELAM, 1996.

. «Una teología inculturada en lengua castellana para dar razón de la esperanza en el siglo XXI». En Sociedad Argentina de Teología, Dar razón de nuestra esperanza, 235-249. Buenos Aires: Ágape, 2012.

González, Marcelo. «Teología de la historia desde la perspectiva argentina. La contribución de Lucio Gera y Rafael Tello». Stromata 58 (2002): 238-246.

. La reflexión teológica en la Argentina, 1962-2004: apuntes para un mapa de sus relaciones y desafíos hacia el futuro. Córdoba: Universidad Católica de Córdoba, 2005.

. «Aportes argentinos a un pensamiento teológico latinoamericano inculturado. Memoria, presente y perspectivas de un cauce teológico». Stromata 58 (2002): 39-205.

Grande, Antonio Mario. Aportes argentinos a la teología pastoral y a la nueva evangelización. Buenos Aires: Ágape, 2011.

Politi, Sebastián. Teología del pueblo. Una propuesta Argentina para Latinoamérica. Buenos Aires: Castañeda, 1992. 
Scannone, Juan Carlos. «"Mestizaje cultural" y "bautismo cultural". Categorías teóricas fecundas para interpretar la realidad latinoamericana». Stromata 33 (1977): 73-91.

. «La teología de la liberación: caracterización, corrientes, etapas». En Teología de la liberación y doctrina social de la Iglesia, 21-80. Madrid-Buenos Aires: Cristiandad-Guadalupe, 1987.

. «Los aportes de Lucio Gera a la teología en perspectiva latinoamericana». En Ferrara, Ricardo y Galli, Carlos María. Presente y futuro de la teología en Argentina. Homenaje a Lucio Gera. Buenos Aires: Paulinas, 1997.

Tello, Rafael. Pueblo y cultura I. Buenos Aires: Patria Grande, 2011. . La Nueva Evangelización. Escritos teológico-pastorales. Buenos Aires: Ágape, 2008.

. Fundamentos de una Nueva Evangelización. Tomo I, $\mathrm{n}^{\mathrm{o}}$ 33, inédito.

- El cristianismo popular según ciertas características, $\mathrm{n}^{\circ}$ 11, inédito.

. Charla de Tapalqué, 14 a 16 de febrero de 1977, inédito.

. Pobres y pobreza, hoy, Cofradía de Luján, folleto $n^{0} 5$, sin fecha, no 12 .

. La pastoral popular y Santo Domingo, $\mathrm{n}^{\circ} 258$, inédito.

. Pastoral popular: nota (g), 389, inédito.

. Sobre cultura moderna. Cuadernillo complementario 2, $\mathrm{n}^{\circ}$ 68, inédito.

. Desgrabación charla 25 de agosto de 1994, inédito, s/n. . Consideración de nuestra historia, $\mathrm{n}^{0} 1$, inédito. 